\title{
A TRANSMISSIBLE PLASMID DETERMINING LACTOSE FERMENT- ATION AND MULTIPLE ANTIBIOTIC RESISTANCE IN A STRAIN OF KLEBSIELLA PNEUMONIAE
}

\author{
H. Williams Smith and Zoe Parsell \\ Houghton Poultry Research Station, Houghton, Huntingdon PE17 2DA
}

IN 1974 a strain of Klebsiella pneumoniae, of capsular type 43 and referred to as L1, was isolated from the River Taff in Wales. In mixed culture it co-transferred its chloramphenicol, ampicillin, tetracycline, streptomycin, spectinomycin and sulphonamide resistance and its ability to ferment lactose to Escherichia coli K12. Because of the possible medical significance of this observation, strain L1 was studied more fully; the results are recorded in this paper.

\section{MATERIALS AND METHODS}

Plasmid transmission. Donor and recipient strains were grown together in nutrient broth (Oxoid no. 2) at $37^{\circ} \mathrm{C}$ for $24 \mathrm{~h}$, and then cultured on plates of solid medium containing an antibiotic, usually sodium nalidixate, to which the recipient was mutationally resistant. For detecting transfer of antibiotic resistance, the medium was MacConkey's agar containing, in addition to sodium nalidixate, an antibiotic to which the donor was resistant. The medium for detecting transfer of lactose fermentation contained (g per litre) $\mathrm{K}_{2} \mathrm{HPO}_{4} 7$, $\mathrm{KH}_{2} \mathrm{PO}_{4} 3,\left(\mathrm{NH}_{4}\right)_{2} \mathrm{SO}_{4} 1, \mathrm{MgSO}_{4} .7 \mathrm{H}_{2} \mathrm{O} 0 \cdot 1, \mathrm{NaCl} 5$, lactose 5, agar 15, supplemented, where necessary, with growth factors, $50 \mu \mathrm{g}$ per ml. All antibiotics were incorporated in culture media at concentrations of $20 \mu \mathrm{g}$ per ml.

Plasmid elimination. This was attempted by the acridine orange method of Hirota (1960), the sodium lauryl sulphate method of Tomoeda et al. (1968) and by passage in broth at $44^{\circ} \mathrm{C}$.

Plasmid transfer in chicks. Groups of chicks in their first day of life were given, by mouth, $0.3 \mathrm{ml}$ of a broth culture of the L1 strain of $K$. pneumoniae in which transfer-factor I (I $d r d 16$; Hardy et al., 1973) or A2 (Smith and Heller, 1973) had been implanted. On the following day the chicks were given a similar dose of a broth culture of a mutant of either Salmonella typhimurium of phage-type 36 or Salmonella gallinarum that was resistant to sodium nalidixate $\left(n a l^{\mathrm{r}}\right)$ and rifampicin $\left(\right.$ rif $\left.^{\mathrm{r}}\right)$. Some of the groups were then fed ordinary diets and others were given food containing $500 \mathrm{mg}$ per $\mathrm{kg}$ of chloramphenicol or ampicillin. Cloacal swabs were taken from the chicks at intervals and inoculated on to plates of Brilliant Green Agar (Oxoid, CM263) containing $20 \mu \mathrm{g}$ per $\mathrm{ml}$ of each of sodium nalidixate and rifampicin. After disks containing $50 \mu \mathrm{g}$ of chloramphenicol were placed on their surface, the plates were incubated at $37^{\circ} \mathrm{C}$ for $24 \mathrm{~h}$ and read. Only the al $^{\mathrm{r}}$ rif $^{\mathrm{r}}$ salmonella organisms grew on this medium; any that had acquired the ability to ferment lactose $\left(\mathrm{Lac}^{+}\right)$grew as pale colonies and any that had acquired chloramphenicol resistance $\left(\mathrm{Cmp}^{+}\right)$grew in the immediate vicinity of the chloramphenicol disks.

Antibiotic-sensitivity tests. These were performed by the disk method described by Smith (1970).

\section{RESULTS}

Strain L1 transferred its resistance to chloramphenicol, ampicillin, tetracycline, streptomycin, spectinomycin and sulphafurazole to a $\mathrm{lac}^{-}$strain of $E$. coli $\mathrm{K} 12$ at the very low rate of approximately $3 \times 10^{-5}$, i.e., three of every $100000 \mathrm{~K} 12$ organisms acquired antibiotic resistance. Each of the antibiotics to which L1 was resistant, except streptomycin, was used separately in the selection plates of MacConkey's agar. All the colonies of K12 that grew

Received 27 Nov. 1975; accepted 23 Dec. 1975.

J. MED. MICROBIOL.—VOL. 9 (1976) 
on these plates were lactose fermenting and two colonies picked from each of the five different kinds of media had acquired the complete antibiotic-resistance pattern of strain L1. When 64 colonies picked from selection plates of the minimal medium, i.e., $\mathrm{Lac}^{+}$colonies, were tested for susceptibility to chloramphenicol, 62 were resistant; one of the remaining two was resistant to ampicillin, tetracycline, streptomycin and spectinomycin and the other to ampicillin and tetracycline. The close relationship between the determinants for antibiotic resistance and lactose fermentation in strain $\mathrm{L} 1$ was also noted in other transfer experiments in which K12 strains were used both as donors and recipients and in all the experiments on genetic transfer and removal described below; for this reason the determinants will be referred to collectively as the $\mathrm{L} 1$ plasmid.

Transfer of the $\mathrm{L} 1$ plasmid to the $l a c^{-} \mathrm{K} 12$ strain occurred at a lower rate at $28^{\circ} \mathrm{C}$ than at $37^{\circ} \mathrm{C}$ and no transfer was detected at $22^{\circ} \mathrm{C}$. Transfer was not detected to 10 of 11 epidemiologically unrelated wild strains of $E$. coli, three strains of Salmonella typhimurium belonging to different phage types, and one strain each of Salm. choleraesuis, Salm. dublin, Salm. thompson, Salm. gallinarum, Shigella flexneri, Sh. sonnei and Proteus mirabilis. It was detected to a Vi strain of Salm. typhi at a rate of $10^{-7}$.

Plasmid-deficient organisms were easily obtained from the L1 strain by passage in broth at $44^{\circ} \mathrm{C}$ but not by sodium lauryl sulphate or acridine orange treatment. Their colonies on MacConkey's agar were pink in colour whereas those of strain L1 were red. The colonies of the two kinds of organism were more sharply differentiated on the minimal medium, those of the plasmid-deficient organisms being much smaller than those of strain L1. The plasmid was transmitted at the relatively high rate of $10^{-2}$ from strain $L 1$ to a culture of the plasmiddeficient organisms, all the colonies of the recipient organisms being red and composed of antibiotic-resistant organisms.

Ten of 23 epidemiologically unrelated strains of $K$. pneumoniae grew as red colonies on MacConkey's agar and 13 as pink ones. None of five red-colony strains transferred their characteristic property to the plasmid-deficient form of strain L1 or to a lac ${ }^{-} \mathrm{K} 12$ strain, but it was eliminated from four of them either by passage in broth at $44^{\circ} \mathrm{C}$ or by sodium lauryl sulphate treatment.

The transfer rate and recipient range of the $\mathrm{L} 1$ plasmid was increased to approximately the same extent by implanting either transfer-factor I or A2 in the L1 strain. This was achieved by implanting in the plasmid-deficient form of the strain first I or A2, with a tetracycline-resistance determinant as marker, and then, from a K12 strain, the L1 plasmid. The transfer rates of the $\mathrm{L} 1$ plasmid from the $\mathrm{I}^{+}$and $\mathrm{A}_{2}{ }^{+}$forms of the $\mathrm{L} 1$ strain to the $l a c^{-} \mathrm{K} 12$ and Salm. typhi strains were approximately $2 \times 10^{-2}$ and $2 \times 10^{-4}$ respectively; the tetracycline-resistance determinant with I or A2 transferred at higher rates indicating that a linkage had not been established between them and the L1 plasmid. Transfer of the L1 plasmid was also detected from these two forms to nine of the eleven wild strains of $E$. coli, the three strains of Salm. typhimurium and the one strain each of Salm. gallinarum, Sh. flexneri and Sh. sonnei at rates of $10^{-3}$ to $10^{-6}$; transfer was not detected to the other three salmonella strains previously employed as recipient strains. It was also not detected to the plasmiddeficient form of strain L1. The numbers of day-old chicks in groups of 25 that died after they had been infected orally with $5 \times 10^{8}$ viable organisms of one of the Salm. typhimurium strains or with a similar dose of organisms of this strain in which the L1 plasmid had been implanted with transfer factor I or A2 were 7,6 and 12 respectively. The corresponding figures for a similar experiment in which the Salm. gallinarum strain was employed instead of the Salm. typhimurium strain were 10, 6 and 13 respectively.

\section{Transfer of the L1 plasmid in chicks}

No evidence of transfer of the L1 plasmid from the $\mathrm{I}^{+}$or $\mathrm{A2}^{+}$forms of the $\mathrm{L} 1$ strain to Salm. typhimurium or gallinarum was detected in groups of 14 chicks given ordinary food or chloramphenicol-containing food after infection. A considerable degree of transfer, however, occurred in the groups given ampicillin-containing food, especially in those infected with the $\mathrm{I}^{+}$form. For example, of the 14 chicks given this form and Salm. typhimurium, the number 
whose faeces were found to contain Salm. typhimurium organisms that were lactose-fermenting and resistant to chloramphenicol, ampicillin, tetracycline, streptomycin, spectinomycin and sulphonamide $4,8,11$ and 14 days after infection were $3,11,13$ and 14 respectively; at least half of the Salm. typhimurium organisms isolated from most of the 41 positive specimens belonged to this category. In the similar experiment employing Salm. gallinarum instead of Salm. typhimurium, Salm. gallinarum organisms possessing the L1 plasmid were found in the faeces of six chicks 3 days after infection. They were not found in the faeces of the four chicks that were still alive after 11 days or in the liver of those that had died by that time. None of the chicks that had been infected with Salm. typhimurium died.

\section{Discussion}

Reeve and Braithwaite (1973) demonstrated that organisms of the genus Klebsiella fall into two classes-those with a strong and those with a weak lactose-positive phenotype. The former owe this phenotype to the presence of a Lac plasmid which could not promote its own transfer but which could be transferred by implanting transfer factors in cells harbouring it. The strains we designated red and pink-colonied undoubtedly correspond to the strong and weak lactose-fermenting phenotypes. The fact that we were able to obtain weakfermenting organisms from strong-fermenting strains by passage in broth at $44^{\circ} \mathrm{C}$ and by sodium lauryl sulphate treatment confirmed the plasmid-determined nature of the strongfermenting property. The L1 strain, however, was exceptional in that its Lac plasmid also determined antibiotic resistance and was transmissible. The transfer factor responsible for its transmissibility did not appear to be located in the plasmid because when I or A2 displaced it, as evidenced by the failure of the $\mathrm{I}^{+}$and $\mathrm{A} 2^{+}$forms of strain $\mathrm{L} 1$ to transmit the plasmid to the plasmid-deficient form of L1, they clearly did not become integrated in the plasmid. The L1 transfer factor transmitted the plasmid to $\mathrm{lac}^{-}$pathogens at very low rates or not at all indicating that strain $\mathrm{L} 1$ was of little medical significance in this particular context. However, the fact that its plasmid was transmitted by transfer factors I and A2 to salmonella organisms in the alimentary tract of chicks fed diets containing ampicillin, suggested that wild forms of strain $L 1$ could be medically significant if they became infected with transfer factors like I and A2.

\section{SUMMARY}

In a wild strain of Klebsiella pneumoniae the plasmid that determined lactose fermentation also determined resistance to chloramphenicol, ampicillin, tetracyclines, streptomycin, spectinomycin, and sulphonamides. The plasmid transferred at a very low rate to Escherichia coli $\mathrm{K} 12$ and Salmonella typhi. By implanting other transfer factors in the strain the rate of transfer and the recipient range were increased. Plasmid transfer from the modified strain to Salm. typhimurium and Salm. gallinarum was detected in the alimentary tract of experimentally infected chicks fed diets containing ampicillin.

We thank Miss Margaret Lovell and Mr P. F. Green for their capable technical help.

\section{REFERENCES}

Hardy, K. G., Meynell, G. G., Dowman, J. E. and Spratt, B. G. 1973. Two major groups of colicin factors; their evolutionary significance. Molec. gen. Genet., 125, 217.

Hirota, Y. 1960. The effect of acridine dyes on mating type factors in Escherichia coli. Proc. natn Acad. Sci., U.S.A., 46, 57.

ReEVE, E. C. R. AND BRAITHWAITE, J. A. 1973. $\mathrm{Lac}^{+}$plasmids are responsible for the strong lactose-positive phenotype found in many strains of Klebsiella species. Genet. Res., 22, 329.

SmITH, H. Williams 1970. The transfer of antibiotic resistance between strains of enterobacteria in chickens, calves and pigs. J. med. Microbiol., 3, 165 . 
Smith, H. Williams and Heller, E. D. 1973. The activity of different transfer factors introduced into the same plasmid-containing strain of Escherichia coli K12. J. gen. Microbiol., 78, 89.

Tomoeda, M., InUzuKa, M., Kubo, N. AND NAKAmuRa, S.1968. Effectiveelimination of drug resistance and sex factors in Escherichia coli by sodium dodecyl sulfate. J. Bact., 95, 1078. 